\title{
SRATEGI PEMANFAATAN INSTAGRAM SEBAGAI MEDIA PERIKLANAN
}

\author{
Saffanah Salma ${ }^{a}$, Cecep Safa'atul Barkah ${ }^{b}$, Tetty Herawaty ${ }^{c}$, Lina Auliana $^{d}$ \\ Program Studi Ilmu Administrasi Bisnis, Universitas Padjadjaran, Indonesia \\ saffanahslm@gmail.com ${ }^{a_{1} \rtimes}$
}

\begin{abstract}
ABSTRAK
Penelitian ini bertujuan untuk mengatahui strategi yang tepat dalam pemanfaatan Instagram sebagai media periklanan pada UMKM Amoira menggunakan metode kualitatif deskriptif, data diambil dengan melakukan two cara yaitu wawancara dan juga observasi. Data yang diperoleh diolah dengan sejumlah metode seperti analisis internal resources, analisis Sustainable Competitive Advantage (SCA), framework VRIO dan juga analisis TOWS. Kemudian peneliti melakukan analisis konten untuk mengusulkan strategi pemanfaatan Instagram. Pada penelitian ini, menghasilkan strategi-strategi yang bisa dilakukan berdasarkan analisis yang dilakukan pada Amoira.
\end{abstract}

Kata kunci: strategi pemanfaat instagram, media periklanan, impression

\begin{abstract}
This research aims to find out the right strategy in using Instagram as an advertising medium for MSMEs in Amoira using descriptive qualitative methods. The data is taken by doing two ways, namely interviews and also observations. The data obtained is processed by several methods such as internal resources analysis, Sustainable Competitive Advantage (SCA) analysis, VRIO framework, and also TOWS analysis. Then the researchers conducted a content analysis to propose strategies for using Instagram. In this study, generate strategies that can be carried out based on the analysis conducted on Amoira.
\end{abstract}

Keywords: instagram utilization strategy, advertising media, impression

\section{PENDAHULUAN}

Pada era digital sekarang ini media sosial memegang peran penting bagi keberlangsungan sebuah bisnis yang mana dapat memberikan peluang dalam memperluas jaringan bisnis seluasnya. Bagi para pelaku bisnis media sosial Instagram dapat memberi kemudahan untuk memperkenalkan dan memasarkan produknya, Instagram tidak hanya memberika kemudahan pada pelaku bisnis tetapi juga kepada konsumen yang mana dapat dengan mudah mencari kebutuhannya.

Salah satu bisnis yang memanfaatkan fitur yang ada di Instagram adalah Amoira, yang merupakan usaha fashion wanita khususnya yang berhijab, berdiri sejak 2012 dengan nama Tabea tetapi berganti kepemilikan pada tahun 2019 dan mengganti namanya dengan Amoira sampai saat ini. Amoira memiliki kurang lebih 142.000 pengikut di Instagram

\footnotetext{
${ }^{1} \rtimes$ : Corresponding author: saffanahslm@gmail.com
} 
dengan 1.769 unggahan didalamnya sampai pada Juni 2021 yang mana saat ini sedang gencar melakukan pemasaran melalui sosial media Instagram dengan memanfaatkan berbagai fitur khususnya Instagram ads dimana merupakan salah satu fitur yang mengambil peran penting dalam memasarkan produk-produk dari Amoira. Saat ini Amoira tengah melakukan promosi pemasaran melalui media sosial Instagram dengan menggunakan fitur Instagram Ads, yang mana setiap melakukan iklan akan menunjukkan berapa jumlah pengguna yang melihat tayangan iklan tersebut. Biasanya pemasar melakukan beberapa kali iklan untuk memasarkan produknya, dengan itu pemasar harus membandingkan iklan yang sudah ditayangkan untuk menentukan strategi kedepannya agar jumlah tayangan iklan semakin meningkat.

Dalam upaya meningkatkan impression iklan terdapat hal-hal yang harus diperhatikan. Pertama pahami target pasar, saat jangkauan iklan yang dibagikan meningkat, otomatis brand awareness meningkat. Oleh karena itu, sangat penting untuk memperluas jangkauan dari iklan yang akan ditayangkan. Kedua, perhatikan Impression secara teratur. Impressions mengukur kemampuan konten untuk muncul di depan audiens yang diinginkan. Saat impressions meningkat, kemungkinan hal ini terjadi karena konten tersebut lebih sering muncul dan dibagikan di media sosial pengguna. Ini berarti konten tersebut telah dioptimasi dengan baik di berbagai media sosial yang kamu targetkan (Beka, 2013; Kenton, 2020).

Dalam mengukur impression dari iklan-iklan yang sudah ditayangkan, pemasar menggunakan cost-per-thousand impression (CPM) untuk membandingkan iklan - iklan tersebut. CPM memungkinkan pemasar untuk membuat perbandingan biaya antara beberapa iklan yang telah ditayangkan. Pemasar menghitung CPM dengan membagi biaya iklan dengan jumlah tayangan (atau peluang untuk dilihat) yang ditampilkan oleh setiap bagian iklan. Karena jumlah tayangan umumnya cukup besar, pemasar biasanya membagi dengan 1.000 yang merupakan standar industri.

$$
\mathrm{CPM}=\frac{\text { Advertasing Cost }}{\text { Impression Generated }(\text { in thousand })}
$$

\section{Tabel 1. Hasil Instagram Ads Amoira}

\begin{tabular}{|c|c|c|}
\hline Cost & Impression & Cost-per-Thousand Impression \\
\hline Rp. 100,000 & 1,125 & Rp.88.892 \\
\hline Rp.200,000 & 2,725 & Rp.73.39 \\
\hline Rp.200,000 & 1,365 & Rp. 146.52 \\
\hline Rp.100,000 & 3,322 & Rp. 30.10 \\
\hline Rp. 495,192 & 20,400 & Rp. 24,27 \\
\hline
\end{tabular}

Berdasakan tabel diatas dapat dilihat bahwa hasil dari CPM Amoira menunjukan hasil yang berbeda-beda walaupun terdapat iklan yang mengeluarkan biaya yang sama dan cenderung mendapatkan impression yang sedikit. Dari permasalahan tersebut, maka rumusan masalahnya adalah bagaimana strategi yang tepat untuk Amoira agar dapat meningkatkan sebanyak 10\% impression dari iklan yang akan ditayangkan agar lebih banyak pengguna yang dapat melihat tayangan? 


\section{KAJIAN LITERATUR Periklanan}

Periklanan merupakan salah satu bentuk promosi untuk menarik perhatian publik mengenai suatu opini, pelayanan atau produk yang disampaikan melalui sebuah media. Iklan adalah bentuk dari kegiatan komunikasi non personal yang disampaikan lewat media dan membayar ruang yang dipakainya untuk menyampaikan pesan yang bersifat membujuk kepada konsumen oleh perusahaan, lembaga non-komersial, maupun pribadi yang berkepentingan (Dunn, 1982). Terdapat beberapa karakteristik atau ciri-ciri dari iklan secara umum yaitu pesan atau informasi yang disampaikan bersifat komunikatif dan informatif, menggunakan bahasa yang bersifat persuasif dan emadukan unsur kata-kata, gambar ataupun suara. Dari penjelasan tersebut dapat dikatakan bahwa iklan sebagai media untuk menarik perhatian dan mendorong atau membujuk orang yang melihat atau membaca iklan tersebut agar memiliki atau memenuhi tujuan dari pemasang iklan.

\section{Media Sosial}

Media sosial adalah medium di internet yang memungkinkan pengguna merepresentasikan dirinya maupun berinteraksi, bekerja sama, berbagi, berkomunikasi dengan pengguna lain membentuk ikatan sosial secara virtual. Dalam media sosial, tiga bentuk yang merujuk pada makna bersosial adalah pengenalan (cognition), komunikasi (communication) dan kerjasama (cooperation) (Nasrullah, 2015). Sedangkan menurut Dijck \& Poell (2013) mengatakan bahwa "Media sosial adalah platform media yang memfokuskan pada eksistensi pengguna yang memfasilitasi mereka dalam beraktifitas maupun berkolaburasi, Karena itu media sosial dapat dilihat sebagai medium( fasilitator) online yang menguatkan hubungan antar pengguna sekaligus sebagai sebuah ikatan sosial.”

\section{Impression Management}

Impression management atau sering disebut dengan manajemen kesan yaitu definisi dari suatu proses yang mana seseorang berusaha untuk dapat mengendalikan atau memanipulasi reaksi orang lain terhadap citra dari diri orang tersebut maupun terhadap ideidenya. Impression management dapat dilakukan dengan mengubah cara berpakaian, mematuhi norma dan peraturan di tempat dia berada, mengambil nama atas pekerjaan orang lain, cara berbicara, cara berjalan dan lain-lain. Semua hal itu dilakukan dengan harapan agar seseorang mendapat pengaruh dari orang yang ditujunya (Kreitner \& Kinichi, 2005). Impression dalam Instagram sama saja dengan ukuran jumlah total yang mengacu pada berapa kali para pengguna melihat iklan yang ditayangkan melalui postingan di Instagram. Jika, iklan yang tampil pada 500 layar pengguna, maka total impression yang dihasilkan adalah 500 Impression.

\section{Brand Awareness}

Brand awareness atau kesadaran merek merupakan kemampuan konsumen untuk mengenali sebuah merek, produk maupun jasa. Menurut Kotler \& Keller (2012) Brand awareness (kesadaran merek) adalah kemampuan untuk mengidentifikasi (mengakui atau mengingat) merek dalam kategori, dengan cukup rinci untuk melakukan pembelian. Brand awareness adalah keterampilan konsumen untuk mengidentifikasi dan mengingat kembali suatu merek merupakan bagian dari kelompok produk tertentu (Aaker, 2013) 


\section{METODE PENELITIAN}

Metode penelitian yang digunakan dalam penelitian ini adalah metode penelitian deskriptif kualitatif. metode penelitian deskriptif-kualitatif bebas mengamati objeknya, menjelajahi, dan menemukan wawasan baru selama penelitian (Ardianto, 2011). Oleh karena itu, metode penelitian ini merupakan sebuah metode yang digunakan peneliti untuk menemukan pengetahuan atau teori terhadap penelitian pada satu waktu tertentu (Mukhtar, 2013). Melalui metode ini penulis berusaha untuk memaparkan hasil daripada penelitian mengenai pemanfaat media sosial Instagram untuk melakukan periklanan dalam memasarkan suatu produk dari Amoira.

Teknik pengumpulan data adalah dengan melakukan wawancara dan observasi, kemudian dengan hasil yang didapat dilakukan analisa dengan alat analisis Keunggulan Kompetitif Berkelanjutan (SCA), analisis TOWS, dan VRIO. Wawancara dilakukan secara online melalui media platform Zoom Meeting dikarenakan adanya pandemi Covid-19, serta melakukan observasi secara online melalui akun media sosial Amoira. Jenis Data yang digunakan berupa data primer dan sekunder. Menurut Hasan (2002) data primer merupakan data yang diperoleh atau dikumpulkan langsung di lapangan oleh orang yang melakukan penelitian atau yang bersangkutan yang memerlukannya. Data primer di dapat dari sumber informan yaitu individu atau perseorangan seperti hasil wawancara yang dilakukan. Dalam konteks ini, data yang dikumpulkan dari wawancara dan observasi informan yang telah ditentukan (purposive sample) terhadap objek penelitian yaitu Amoira. Sedangkan data sekunder mengacu pada informasi penelitian yang berasal dari dokumentasi atau bahan pustaka seperti buku, catatan, dan jurnal, serta bukti-bukti yang terkait dengan topik kajian berupa arsip yang ada dan tidak terkait.

\section{HASIL PENELITIAN DAN PEMBAHASAN Analisis Internal Resouces}

Analisis internal resources (Tabel 2) merupakan suatu pemeriksaan terperinci yang berfokus pada elemen sumber daya, kemampuan, dan kompetensi suatu perusahaan yang tujuannya adalah menentukan kekuatan dan kelemahan perusahaan. Dengan melakukan analisis internal dapat diketahui kelebihan dan kekurangan pada pesaing yang bisa digunakan sebagai peluang untuk dijadikan sebagai strategi baru.

a. Tangible, Tangible adalah aset fisik yang bisa diartikan sebagai aset yang dapat dihitung, dilihat dan diraba fisiknya secara langsung.

b. Intangible, Intangible merupakan kebalikan dari tangible yang mana merupakan aset perusahaan yang tidak bisa dihitung maupun dilihat langsung secara fisik. Contoh dari Intangible atau aset yang tak berwujud adalah: Hak paten, goodwill dan lain sebagianya.

Berdasarkan tabel 2 dapat dilihat bahwa Amoira terdapat 8 tangible dan 2 intangible dengan kapabilitasnya masing-masing. Dalam melakukan analisis internal resouces ini dilakukan juga analisis pada dua kompetitor Amoira yaitu ninette dan semibydianty. 
Tabel 2. Analisis Internal Resources

\begin{tabular}{|c|c|c|}
\hline No & Resources & Capabilities \\
\hline 1 & \multicolumn{2}{|l|}{ A. Tangible } \\
\hline \multirow[b]{2}{*}{2} & & Supplier dengan gratis ongkir \\
\hline & Transportasi & $\begin{array}{l}\text { Kapasitas pengiriman disesuaikan dengan pemesanan, apabila } \\
\text { pesanan sedikit - sedang maka menggunakan mobil / layanan } \\
\text { jasa antar dengan mobil. Apabila pesanan sedang banyak dapat } \\
\text { menggunakan mobil box. }\end{array}$ \\
\hline \multirow{3}{*}{3} & \multirow{3}{*}{ Lahan } & Garasi ukuran $3 \times 4 \mathrm{~m}$ \\
\hline & & Rumah Owner tepatnya garasi \\
\hline & & Memiliki penilaian 4,9/5 pada shopee \\
\hline 4 & Wifi & Terdapat wifi untuk kelangsungan bisnis dengan 100mbps \\
\hline 5 & Komputer / Laptop & Laptop pribadi (2 laptop) \\
\hline 6 & Keuangan & Keuangan Amoira berkembang atau meningkat, profitable \\
\hline 7 & $\begin{array}{l}\text { Technological Aspect - } \\
\text { Instagram }\end{array}$ & $\begin{array}{l}\text { Memiliki } 142 \mathrm{k} \text { followers di Instagram dengan engagement rate } \\
\text { sebesar } 0.23 \%\end{array}$ \\
\hline \multirow[t]{2}{*}{8} & $\begin{array}{l}\text { Technological Aspect - e- } \\
\text { commerce }\end{array}$ & $\begin{array}{l}\text { Memiliki } 13 \mathrm{k} \text { followers di e-commerce dengan rating } 4.9 / 5 \\
\text { bintang, Amoira hanya fokus pada satu e-commerce saja yaitu } \\
\text { Shopee. }\end{array}$ \\
\hline & \multicolumn{2}{|l|}{ B. Intangible } \\
\hline \multirow{2}{*}{1} & \multirow{2}{*}{ Brands } & $\begin{array}{l}\text { Nama Brand dan Logo terdaftar pada Hak Kekayaan } \\
\text { Intelektual (mempunyai trademarks) }\end{array}$ \\
\hline & & $\begin{array}{l}\text { Mempunyai reputasi sebagai brand fashion hijab dengan style } \\
\text { korea }\end{array}$ \\
\hline 2 & Customer Relation & Mempunyai 140.000 followers \\
\hline
\end{tabular}

\section{Framework for analysis : VRIO}

Setelah melakukan analisis internal, selanjutnya melakukan analisis framework VRIO yang disusun dengan tujuan untuk menganalisis lebih lanjut mengenai aktivitas bisnis dan kapabilitas dari suatu perusahaan, mengenai values (nilai), rarity (kelangkaan), imitability (kemungkinan peniruan), dan organisasi. Hasilnya dapat mengidentifikasikan apakah sebuah sumber daya atau kemampuan yang dimiliki dapat menjadi kekuatan atau kelemahan bagi perusahaan (Tabel 3).

Tabel 3. Analisis VRIO

\begin{tabular}{|c|l|c|c|c|c|c|c|}
\hline No & $\begin{array}{c}\text { Types of } \\
\text { Capabilities }\end{array}$ & $\begin{array}{c}\text { Valua- } \\
\text { ble }\end{array}$ & Rare & $\begin{array}{c}\text { Costly } \\
\text { to } \\
\text { initiate }\end{array}$ & $\begin{array}{c}\text { Non- } \\
\text { Substituable }\end{array}$ & $\begin{array}{c}\text { Competitive } \\
\text { Consequence }\end{array}$ & $\begin{array}{c}\text { Performance } \\
\text { Implications }\end{array}$ \\
\hline 1 & $\begin{array}{l}\text { Supplier } \\
\text { dengan } \\
\text { gratis ongkir }\end{array}$ & Yes & Yes & Yes & Yes & $\begin{array}{l}\text { Suistainable } \\
\text { Competitive } \\
\text { Advantage }\end{array}$ & $\begin{array}{c}\text { Above Average } \\
\text { Return }\end{array}$ \\
\hline 2 & $\begin{array}{l}\text { Kapasitas } \\
\text { pengiriman } \\
\text { disesuaikan } \\
\text { dengan } \\
\text { pemesanan }\end{array}$ & Yes & No & No & No & $\begin{array}{c}\text { Competitive } \\
\text { Parity }\end{array}$ & Average Return \\
\hline 3 & $\begin{array}{l}\text { Ukuran } \\
\text { garasi }\end{array}$ & Yes & No & No & No & $\begin{array}{c}\text { Competitive } \\
\text { Parity }\end{array}$ & Average Return \\
\hline
\end{tabular}


Tabel 3. Analisis VRIO (lanjutan)

\begin{tabular}{|c|c|c|c|c|c|c|c|}
\hline No & $\begin{array}{c}\text { Types of } \\
\text { Capabilities }\end{array}$ & $\begin{array}{l}\text { Valua- } \\
\text { ble }\end{array}$ & Rare & $\begin{array}{c}\text { Costly } \\
\text { to } \\
\text { initiate }\end{array}$ & $\begin{array}{c}\text { Non- } \\
\text { Substituable }\end{array}$ & $\begin{array}{c}\text { Competitive } \\
\text { Consequence }\end{array}$ & $\begin{array}{l}\text { Performance } \\
\text { Implications }\end{array}$ \\
\hline 4 & $\begin{array}{l}\text { Lahan } \\
\text { pribadi }\end{array}$ & Yes & No & No & No & $\begin{array}{l}\text { Competitive } \\
\text { Parity }\end{array}$ & Average Return \\
\hline 5 & $\begin{array}{l}\text { Kekuatan } \\
\text { Wifi }\end{array}$ & Yes & No & Yes & Yes & $\begin{array}{l}\text { Suistainable } \\
\text { Competitive } \\
\text { Advantage }\end{array}$ & $\begin{array}{l}\text { Above Average } \\
\text { Return }\end{array}$ \\
\hline 6 & $\begin{array}{l}\text { Laptop } \\
\text { pribadi }\end{array}$ & Yes & No & Yes & Yes & $\begin{array}{l}\text { Suistainable } \\
\text { Competitive } \\
\text { Advantage }\end{array}$ & $\begin{array}{l}\text { Above Average } \\
\text { Return }\end{array}$ \\
\hline 7 & $\begin{array}{l}\text { Keuangan } \\
\text { yang } \\
\text { profitable }\end{array}$ & Yes & No & Yes & No & $\begin{array}{c}\text { Competitive } \\
\text { Parity }\end{array}$ & Average Return \\
\hline 8 & $\begin{array}{l}\text { Followers di } \\
\text { E-commerce }\end{array}$ & Yes & No & No & Yes & $\begin{array}{c}\text { Competitive } \\
\text { Parity }\end{array}$ & Average Return \\
\hline 9 & $\begin{array}{l}\text { Rating di E- } \\
\text { Commerce }\end{array}$ & Yes & Yes & Yes & Yes & $\begin{array}{l}\text { Suistainable } \\
\text { Competitive } \\
\text { Advantage }\end{array}$ & $\begin{array}{c}\text { Above Average } \\
\text { Return }\end{array}$ \\
\hline 10 & $\begin{array}{l}\text { Nama Brand } \\
\text { dan Logo } \\
\text { terdaftar } \\
\text { pada Hak } \\
\text { Kekayaan } \\
\text { Intelektual } \\
\text { (mempunyai } \\
\text { trademarks) }\end{array}$ & Yes & Yes & Yes & Yes & $\begin{array}{c}\text { Suistainable } \\
\text { Competitive } \\
\text { Advantage }\end{array}$ & $\begin{array}{l}\text { Above Average } \\
\text { Return }\end{array}$ \\
\hline 11 & $\begin{array}{l}\text { Mempunyai } \\
\text { reputasi }\end{array}$ & Yes & Yes & Yes & Yes & $\begin{array}{c}\text { Suistainable } \\
\text { Competitive } \\
\text { Advantage }\end{array}$ & $\begin{array}{c}\text { Above Average } \\
\text { Return }\end{array}$ \\
\hline 12 & $\begin{array}{l}\text { Mempunyai } \\
\text { followers di } \\
\text { Instagram }\end{array}$ & Yes & No & No & Yes & $\begin{array}{l}\text { Competitive } \\
\text { Parity }\end{array}$ & Average Return \\
\hline 13 & $\begin{array}{l}\text { Memiliki } \\
\text { engagement } \\
\text { rate di } \\
\text { Instagram }\end{array}$ & Yes & No & No & Yes & $\begin{array}{l}\text { Competitive } \\
\text { Parity }\end{array}$ & Average Return \\
\hline
\end{tabular}

\section{Sustainable Competitive Advantage (SCA)}

SCA merupakan suatu keadaan atau kondisi dimana suatu perusahaan diharapkan dapat mempertahankan posisi bisnis yang menguntungkan atau unggul dalam bersaing pada beberapa tahun mendatang. SCA berfokus pada kepentingan perusahaan untuk menerapkan strategi yang berbeda dari perusahaan kompetitornya. Dalam hal ini berarti bahwa diperlukan penelusuran terhadap inovasi bagi perusahaan untuk dapat menciptakan hal berbeda dan unik untuk dapat menarik minat dan perhatian masyarakat.

Dari hasil analisis VRIO didapatkan bahwa Amoira dapat menghemat biaya pengeluarannya karena memiliki supplier yang memberikan gratis ongkos kirim. Amoira juga memiliki laptop dan jaringan Wifi stabil yang mana sangat penting karena dapat memudahkan menjalankan bisnisnya. Dikarenakan saat ini E-commerce merupakan suatu wadah online untuk melangsungkan transaksi penjualan, maka rating yang didapat bagi sebuah bisnis yang menjual produknya di sebuah E-commerce merupakan hal yang penting karena dapat mencerminkan kualitas dari bisnis tersebut, Amoira sendiri memiliki rating 4,9/5 pada Shopee dan sekaligus menandakan reputasi yang baik. Amoira sudah 
mendaftarkan nama brand dan logonya agar tidak dapat ditiru atau pun dipergunakan oleh orang lain dan sekaligus mendapatkan perlindungan secara hukum.

Tabel 4. Analisis SCA

\begin{tabular}{|c|l|}
\hline No & \multicolumn{1}{|c|}{ SCA } \\
\hline 1 & Supplier dengan gratis ongkir \\
\hline 2 & Kekuatan Wifi \\
\hline 3 & Laptop pribadi \\
\hline 4 & Rating di E-Commerce \\
\hline & $\begin{array}{l}\text { Nama Brand dan Logo terdaftar pada Hak Kekayaan Intelektual (mempunyai } \\
\text { trademarks) }\end{array}$ \\
\hline 6 & Mempunyai reputasi \\
\hline
\end{tabular}

\section{Analisis TOWS}

Menurut Galavan (2004), analisis SWOT merupakan analisis yang memiliki tujuan untuk menciptakan strategi yang tepat dan efektif yang digunakan perusahaan sesuai dengan pasar dan kondisi saat itu. Untuk analisis peluang dan ancaman perusahaan diterapkan untuk mengetahui lingkungan eksternal perusahaan, sedangkan kekuatan dan kelemahan diperoleh melalui analisis internal perusahaan pada Tabel 5 berikut.

Tabel 5. Analisis TOWS

\begin{tabular}{|c|c|c|c|}
\hline \multicolumn{4}{|c|}{ strenght } \\
\hline No & Indikator & Kondisi Saat ini & $\begin{array}{c}\text { Urgensi } \\
\text { Penanganan }\end{array}$ \\
\hline 1 & $\begin{array}{l}\text { Memiliki target pasar yang jelas dan } \\
\text { terkerucut }\end{array}$ & 2 & 4 \\
\hline 2 & $\begin{array}{l}\text { Produk yang dikeluarkan sesuai dengan } \\
\text { kebutuhan masyarakat Indonesia akan } \\
\text { Korean Style fashion yang hijab-friendly }\end{array}$ & 2 & 4 \\
\hline 3 & $\begin{array}{l}\text { Memiliki followers yang cukup di sosial } \\
\text { media Instagram maupun e-commerce } \\
\text { Shopee }\end{array}$ & 4 & 2 \\
\hline 4 & $\begin{array}{l}\text { Kepuasan konsumen sangat baik terlihat } \\
\text { dari rating konsumen }\end{array}$ & 2 & 4 \\
\hline 5 & $\begin{array}{l}\text { Memiliki series dengan nama yang unik } \\
\text { sehingga berbeda dengan pesaing lain dan } \\
\text { model pakaian yang variatif }\end{array}$ & 1 & 3 \\
\hline 6 & $\begin{array}{l}\text { Harga produk terjangkau dengan kualitas } \\
\text { yang baik }\end{array}$ & 3 & 3 \\
\hline \multicolumn{4}{|c|}{ Opportunity } \\
\hline No & Indikator & Kondisi Saat ini & $\begin{array}{c}\text { Urgensi } \\
\text { Penanganan }\end{array}$ \\
\hline 1 & Melakukan penjualan di luar negeri & 2 & 3 \\
\hline 2 & Membuka toko atau butik (fisik) & 5 & 5 \\
\hline 3 & $\begin{array}{l}\text { Membuka kesempatan reseller (skema } \\
\text { b2b) }\end{array}$ & 1 & 2 \\
\hline 4 & Bertambahnya pengguna hijab & 2 & 3 \\
\hline 5 & Adanya loyalitas konsumer & 1 & 1 \\
\hline 6 & Hubungan baik dengan distributor & 2 & 2 \\
\hline
\end{tabular}


Tabel 5. Analisis TOWS (lanjutan)

\begin{tabular}{|c|l|c|c|}
\hline \multicolumn{3}{|c|}{ Weakness } \\
\hline No & \multicolumn{1}{|c|}{ Indikator } & Kondisi Saat ini & $\begin{array}{c}\text { Urgensi } \\
\text { Penanganan }\end{array}$ \\
\hline 1 & Belum mencapai pasar luar negeri & 2 & 2 \\
\hline 2 & Belum mempunyai toko fisik & 5 & 5 \\
\hline 3 & Tidak berjalannya skema b2b atau reseller & 2 & 2 \\
\hline 4 & Produk tidak selalu ready stock & 1 & 2 \\
\hline 5 & $\begin{array}{l}\text { Hanya mengandalkan satu channel } e- \\
\text { commerce }\end{array}$ & 1 & 1 \\
\hline 6 & Kurangnya SDM Perusahaan & 2 & Urgensi \\
\hline & \multicolumn{1}{|c|}{ Threats } \\
\hline No & \multicolumn{2}{|c|}{ Penanganan } \\
\hline 1 & Banyak pesaing dengan produk sejenis. & 2 \\
\hline 2 & $\begin{array}{l}\text { Perkembangan dalam dunia fashion yang } \\
\text { sangat cepat berubah seiring munculnya } \\
\text { trend baru }\end{array}$ & 1 & 2 \\
\hline 3 & Persaingan harga semakin ketat di pasaran & 2 & 2 \\
\hline 4 & Kenaikan harga dari distributor & 3 & 4 \\
\hline 5 & $\begin{array}{l}\text { Perekonomian nasional yang tidak stabil } \\
\text { menyebabkan perubahan daya beli } \\
\text { masyarakat }\end{array}$ & 4 & 1 \\
\hline 6 & $\begin{array}{l}\text { Konsumen mempunyai banyak pilihan } \\
\text { dan pertimbangan terhadap merk lain }\end{array}$ & 2 & 4 \\
\hline
\end{tabular}

Penilaian kondisi saat ini dan urgensi penanganan menggunakan skala 1-5, dengan mengindikasikan 1 sangat kuat, 2 kuat, 3 biasa saja, dan 5 sangat tidak kuat. Dari analisis diatas diambil delapan issue terkait yang perlu diselesaikan (Tabel 6). Setelah melakukan analisis mengenai isu-isu terkait TOWS, maka isu-isu tersebut dikaitkan dengan topik penelitian, yaitu meningkatkan brand awareness. Delapan isu tersebut dinilai keterkaitannya dengan skala 1-5. Skala 1 diartikan sangat tidak terkait, skala 2 tidak terkait, skala 3 cukup terkait, skala 4 terkait, dan skala 5 sangat terkait. Maka, isu yang akan diangkat adalah isu dengan skala 4 dan 5 .

Tabel 6. Isu Terkait

\begin{tabular}{|c|l|c|}
\hline No & \multicolumn{1}{|c|}{ Issue Penyelesaian Masalah } & Keterkaitan dengan Business Issue \\
\hline 1 & $\begin{array}{l}\text { Memiliki followers yang cukup di sosial media } \\
\text { Instagram maupun } \text {-commerce Shopee }\end{array}$ & 5 \\
\hline 2 & $\begin{array}{l}\text { Kepuasan konsumen sangat baik terlihat dari } \\
\text { rating konsumen }\end{array}$ & 3 \\
\hline 3 & Kesempatan Reseller & 5 \\
\hline 4 & Loyalitas Konsumer & 1 \\
\hline 5 & Produk tidak ready stock & 3 \\
\hline 6 & Hanya mengandalkan 1 channel e-commerce & 5 \\
\hline 7 & Perkembangan Trend & 3 \\
\hline 8 & Konsumen punya banyak pilihan merk lain & \\
\hline
\end{tabular}




\section{Identifikasi usulan program}

Berdasarkan hasil analisis internal Amoira, usulan program yang tepat adalah dengan meningkatkan brand awareness. Tujuan meningkatkannya brand awareness adalah membangun kesadaran dan kesan positif konsumen terhadap produk, bisnis, ataupun perusahaan. Dalam meningkatkan brand awareness Amoira terdapat beberapa jenis impression yang dapat menunjang pertumbuhan sebuah akun Instagram agar sebuah akun berkembang lebih cepat. Berikut merupakan beberapa jenis postingan yang dapat menunjang perkembangan akun instagram, yaitu:

a. Home: Berasal dari Feeds Follower.

b. Profile: Berasal dari orang yang berkunjung di Profile.

c. Hashtag: Berasal dari pencarian di Hashtag.

d. Location: Berasal dari pencarian melalui lokasi.

e. Explore: Berasal dari halaman Explore Instagram.

f. Other: Berasal dari share, story share, dan lainnya.

\section{Pelibatan pelanggan dalam memasarkan produk}

\section{Input,}

Pada saat pelanggan membeli produk Amoira terdapat beberapa dari mereka membagikan gambar atau video yang melibatkan Amoira didalamnya. Hal tersebut merupakan kesempatan bagi Amoira untuk memanfaatkannya dengan mengintegrasikan konten tersebut pada perencanaan dan strategi Instagram Ads yang akan dibuat.

2. Process

Disaat pelanggan membagikan gambar atau video nya di Instagram, dapat dimanfaatkan sebagai konten dalam Instagram ads. Karena, menampilkan foto orang nyata pada Instagram Ads akan lebih menarik perhatian calon konsumen karena didalamnya tidak hanya untuk menjual produk saja tetapi juga dapat membantu calon konsumen lainnya dalam menyelesaikan masalah yang sedang dihadapinya yang sekaligus dapat terbantu dengan produk yang ditawarkan.

3. Output

Foto atau video yang dibagikan oleh pelanggan di integrasikan menjadi Instagram ads, dapat berupa postingan berbentuk feeds maupun instastory.

4. Outcome

Meningkatnya followers, engagement rate dan kepercayaan calon konsumen yang mana konsumen mempunyai pengetahuan mengenai suatu objek sekaligus dengan atribut dan manfaatnya.

5. Benefit

Dengan meningkatnya followers, engagement rate dan kepercayaan calon konsumen membuat Amoira dapat dikenal secara luas dan dipercaya oleh calon konsumen. Hal tersebut juga akan membuat Amoira terjadi peningkatan pada penjualan produknya.

6. Impact

Melalui dilibatkannya pelanggan dalam melangsungkan Instagram ads tersebut juga diharapkan akan memberikan kepuasan bagi pihak pelanggan karena sekaligus dapat mempromosikan platform Instagram pribadinya. Instagram ads tersebut juga dapat memberikan peningkatan pada brand awareness dan penjualan produk

\section{PENUTUP}

Kesimpulan dari penelitian ini adalah peneliti mengusulkan untuk melibatkan pelanggan dalam memanfaatkan Instagram sebagai media periklanan, peneliti menggunakan analisis internal resources dengan tujuan mengidentifikasi kekuatan dan kelemahan 
perusahaan. Selanjutnya, melakukan analisis menggunakan kerangka VRIO untuk mendapatkan Sustainable Competitive Advantage (SCA) dari Amoira. Setelah mendapatkan SCA peneliti melakukan analisis TOWS untuk mengetahui keadaan Amoira berasarkan faktor lingkungan internal maupun eksternal. Dari hasil analisis tersebut, terpilihlah indikator peningkatan brand awareness sebagai isu permasalahan.

Setelah itu hasil dari analisis yang sudah dilakukan yaitu analisis internal resources, sustainable competitive advantage (SCA), VRIO dan TOWS menjadi dasar dari keputusan dan usulan program yang ada, yaitu dengan melibatkan pelanggan dalam memasarkan produk Amoira. Melalui strategi ini selain bertujuan untuk meningkatkan awareness calon konsumen terhadapat Amoira, tetapi diharapkan iklan yang dibuat bukan hanya bertujuan untuk menawarkan produk yang akan dijual saja tetapi juga diharapkan dapat membantu calon konsumen dalam menyelesaikan masalah yang sedang dihadapinya yang sekaligus dapat terbantu dengan membeli produk yang ditawarkan dari Amoira.

\section{DAFTAR RUJUKAN}

Ardianto, E. (2011). Metodologi Penelitian untuk Public Relation: Kuantitatif dan kualitatif. Rosdakarya.

Beka, R. (2013). Impression Management in the Marketing Context. Mediterranean Journal of Social Sciences, 4(11), 463-466.

Dijck, J. van, \& Poell, T. (2013). Understanding Social Media Logic. Media and Communication, 1(1), 2-14.

Dunn, S. W. (1982). Advertising : Its Role in Modern Marketing (5th ed.). The Dryden Press.

Galavan, R. (2004). Doing Business Strategy. In In: O'Connor, M., Mangan, J. and Cullen, J., (Eds) IMI Handbook of Management, (pp. 365-392). Oak Tree Press.

Hasan, M. I. (2002). Pokok-Pokok Materi Metodologi Penelitian dan Aplikasinya. Penerbit Ghalia Indonesia.

Kenton, W. (2020). Impression. Marketing Essentials. https://www.investopedia.com/terms/i/impression.asp

Kotler, P., \& Keller, K. L. (2012). Marketing Management (14th ed.). Prentice-Hall.

Kreitner, R., \& Kinichi, A. (2005). Perilaku Organisasi. Salemba Empat.

Nasrullah, R. (2015). Media Sosial; Persfektif Komunikasi, Budaya, dan Sosioteknologi. Bandung: Simbiosa Rekatama Media

Mukhtar. (2013). Metode Praktis Penelitian Deskriptif Kualitatif (Jakarta). GP Press Group. 